\title{
Opferbeschreibungen in christlichen Schriften
}

\author{
Von Jón HNEFILL AðALSTEINSSON
}

In altisländischen Schriften gibt es viele Notizen über Opfer und an einzelnen Stellen wird über die Durchführung der Opferung ausführlich berichtet. Alle diese Berichte sind von christlichen Autoren geschrieben worden. Der älteste Sagaschreiber Islands, Ari der Gelehrte, hat als erster über Geschichtliches in "nordischer Sprache" geschrieben, wie es hieß. Ari war Priester, und seine schriftstellerische Tätigkeit wurde von beiden isländischen Bischöfen beaufsichtigt. Das frühe Sagaschreiben in Island wurde also von den Ansichten der isländischen Kirche sehr beeinflußt.

In meiner Vorlesung werde ich nur einen kleinen Teil der erwähnten Opferbeschreibungen behandeln. Meine Auswahl beschränkt sich auf die Beschreibungen in dem Landnahmebuch (Landnáma, oder Landnámabók) und in einigen Isländersagas.

Die Landnahme Islands begann kurz nach 870 und um 930 war das Land als voll besiedelt anzusehen. Diese sechzig Jahre werden meistens die Landnahmezeit genannt. Ab der Landnahmezeit war der herrschende Glaube in Island die nordgermanische Religion, aber als 999/1000 das Christentum eingeführt wurde, wurde jegliche Opferung abgeschafft, nur die Geheimopfer waren noch eine Zeitlang erlaubt, wenn es keine Zeugen dabei gab. Einige Jahre später wurden aber auch die Geheimopfer abgeschafft, und ab dann war jegliche Opferung in Island durch Gesetz verboten (Aðalsteinsson 1978, 79 ff.).

Das Landnahmebuch - Landnámabók - ist eine Quellenschrift über die Besiedler Islands. In diesem Buch werden rund 400 Siedler aufgezählt und das Landgebiet, das jeder sich angeeignet hat, wird abgegrenzt. An die Hälfte dieser Siedler wird näher beschrieben, und es wird vermerkt, daß die Mehrheit aus Norwegen gekommen sei. Ungefähr 50 sollen von den britischen Inseln gekommen sein, manche nach kurzem Aufenthalt in Irland oder Schottland. Es zählt zur Ausnahme, wenn die Religion der Siedler erwähnt wird. Über einige der Siedler, die aus Schottland oder Irland gekommen waren, wird allerdings mitgeteilt, daß sie als Christen nach Island gekommen seien. 
Es wird aber hinzugefügt, daß unter ihren Nachkommen, die die nordgermanische Religion angenommen haben, die christliche Religion sich nicht gehalten habe. Desweiteren steht im Landnahmebuch, daß die nordgerrmanische Religion "einhundert Winter" in Island geherrscht habe, also ungefähr 120 Jahre (Landnámabók 1968, 396). An einigen Stellen im Landnahmebuch befinden sich besondere Aufzeichnungen über Opferungen.

Die älteste Fassung des Landnáma stammt von ungefähr 1100. In einem Belegmaterial wird erwähnt, daß Kolskegg der Gelehrte Mitverfasser dieses ältesten Landnahmebuches gewesen sei. Es wird auch allgemein angenommen, daß Ari der Gelehrte an diesem ältesten Landnahmebuch gearbeitet hat (Jóhannesson 1941, 221 ff.) Die Möglichkeit, daß die Initiative $z u$ diesem Werk von dem Bischof Islands ausgegangen ist, wird nicht ausgeschlossen (Pétursson 1986, 213). Diese älteste Fassung des Landnáma ist verschollen, aber der Inhalt ist in den späteren Fassungen bewahrt worden. Auf deren Grundlage werden aber nur mehr oder weniger glaubhafte Hypothesen darüber aufgestellt, was in diesem ältesten Landnahmebuch gestanden haben mag.

Rund 100 Jahre, nachdem das erste Landnahmebuch geschrieben worden war, stellte Styrmir Kárason der Gelehrte ein Buch über die Landnahme zusammen, das "Styrmisbuch" genannt wurde. Diese Fassung ist auch verschollen, aber durch die neueren Fassungen kann. man sich den Inhalt einigermaßen vorstellen. Diese späteren Fassungen sind das Sturlabuch, geschrieben von Sturla Pórðarson, aller Wahrscheinlichkeit nach 1263-1271, das Melabuch von ca. 1300, das nur zum Teil bewahrt geblieben ist, und das Hauksbuch aus den ersten Jahrzehnten des 14. Jahrhunderts, geschrieben von Haukur Erlendsson. Schließlich kommen das Skarðsárbuch und das Porðarbuch aus der ersten Hälfte des 17. Jahrhunderts.

Jón Jóhannesson hat (Jóhannesson 1941, 226) über den Zusammenhang der einzelnen Landnahmefassungen geschrieben. Seine Vorstellung über diesen Zusammenhang wird durch die Skizze auf der folgenden Seite beleuchtet.

Sveinbjörn Rafnsson hat im Jahre 1974 über den Zusammenhang einzelner Landnahmefassungen geschrieben, und er hat einen etwas komplizierteren Zusammenhang zwischen den einzelnen Manuskripten aus dem Mittelalter angenommen (Rafnsson 1974, 81). Der Unterschied zwischen den Ansichten von Jóhannesson, Rafnsson und anderen, die sich mit dem Zusammenhang der Landnahmefassungen beschäftigt haben, spielt keine große Rolle bei der Untersuchung, die 


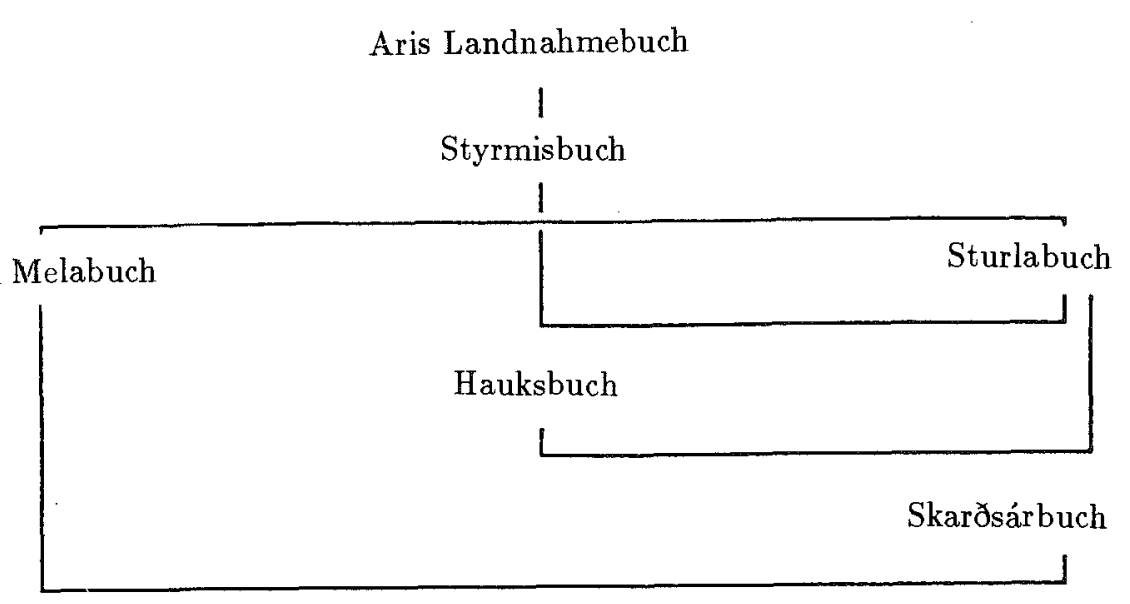

Pórðarbuch

hier durchgeführt wird. Am wichtigsten ist hier, wie viele der Erzählungen, die die Besiedlung des Landes nicht direkt berühren, in der ältesten Fassung des Landnáma vorhanden waren. Hier geht es vor allem um Opferbeschreibungen, aber ihr Quellenwert hängt natürlich davon $a b$, wann sie in den Stoff des Landnahmebuches aufgenommen wurden. Sollte begründet werden können, daß die erwähnten Opferbeschreibungen in der Fassung von Ari vorhanden gewesen sind, wird deren Quellenwert viel größer, als wenn die erwähnte Beschreibung aller Wahrscheinlichkeit nach erst in die jüngeren Fassungen des Landnahmebuches aufgenommen worden sind.

Beginnen wir mit den Aufzeichnungen über Opfer im Landnahmebuch (Landnáma). Im Hauksbuch wird folgendermaßen von Flóki Vilgerðarson erzählt, der noch vor der eigentlichen Landnahmezeit nach Island gesegelt war:

Hann fekk at blóti miklu ok blótaði hrafna prjá, pá er honum skyldu leið visa (Landnámabók 1968, 37).

(Er veranstaltete ein großes Opfer und ofperte dreien Raben, die ihm den Weg weisen sollten).

Als Flóki auf das offene Meer zwischen den Färöern und Island heraus- 
gekommen war, liß er die drei Raben los, einen nach dem anderen. Der erste flog zu den Färöern zurück, der zweite flog hoch in die Luft und dann zum Schiff zur ück, aber der dritte flog über den Bug des Schiffes in die Richtung, wo sie später das Land gefunden haben.

Es ist viel geschrieben worden über Flóki und seine Raben, und einige Forscher haben den Überlieferungswert dieser Erzählung bezweifelt. Es wurde wiederholt behauptet, daß ein Zusammenhang bestünde zwischen der Geschichte, als Noah den Raben aus seiner Arche wegfliegen liess und der Geschichte über die Raben von Flóki. (Land námabók 1968, 37 und Zitate). Es besteht nicht die Möglichkeit, diesen Mutmaßungen hier nachzugehen, es sollte aber darauf aufmerksam gemacht werden, daß es in der Bibelerzählung keine Zeremonie ist, wenn der Rabe freigelassen wird. Das Opfer, von dem im Hauksbuch erzählt wird, ist einmalig. Außerdem soll betont werden, daß es laut Hauksbuch für Flóki günstig war, die Raben geopfert zu haben. Die Raben, die durch das Opfer geweiht wurden, haben direkt dazu beigetragen, daß er das Land gefunden hat (Lange 1968, 356).

Von dem ersten Siedler Islands, Ingólf, und seinem Pflegebruder Hjörleif, wird folgende Geschichte über die Zeit vor ihrer Abreise von Norwegen erzählt:

Đenna vetr fekk Ingólfr at blóti miklu ok leitadi sér heilla um forlög sín, en Hjörleifr vildi aldri blóta (Landnámabók 1968, 42).

(In jenem Winter veranstaltete Ingolf ein großes Opfer und bat um Heil für sein Schicksal. Hjörleif aber wollte nie opfern).

Diese Erzählung wird von der Hand des Landnámaschreibers her unparteiisch vermittelt. Die Bemerkung, daß Hjörleif nicht hat opfern wollen, ist nur gemacht worden, um den Bericht von seinem Schicksal vorzubereiten, und sie weist auch auf Ingólfs Bemerkung hin, als er seinen Pflegebruder ermordet sieht:

... sé ek svá hverjum verða, ef eigi vill blóta (Landnámabók 1968, 44).

(... so sehe ich es jedem ergehen, der nicht opfern will.)

Diese Bemerkung Ingólfs besagt zweierlei: erstens, daß es tadelnswert sei, nicht zu opfern und zweitens, daß es für jedermann eine Notwendigkeit sei, zu opfern, wolle er sich ein langes und glückliches Leben sichern. Es soll darauf hingewiesen werden, daß Ingólf, der diese weisen Worte spricht, als erster Siedler in den Überlieferungen äußerst hochgeschätzt war. In dem Islendingabók sagt Ari der Gelehrte, daß Ingólf wahrscheinlich der erste gewesen sei, der Norwegen verlassen 
und sich in Island niedergelassen habe, und im Landnámabuch steht, daß Ingólfs Nachkommen waren im Lande noch viele Generationen hindurch mächtig (Landnámabók 1968, 46-47).

In dem Landnámabuch wird über Glauben und Opfer von Thorolf Mostrarskegg (Mosterbart) folgendermaßen berichtet:

Pórólfr [...] Mostrarskegg [...] var blótmaðr mikill ok trúði á Pór. [...] skaut hann fyrir borð öndvegissúlum sínum; par var skorinn á Pórr. Hann mælti svá fyrir, at Pórr skyldi par á land koma, sem hann vildi að pórólfr byggði [.. ] pat heitir nú Pórsnes [.. . ] par á nesinu [.. ] hafðði Dórólfr dóma alla, ok par var sett heraðsping með ráđi allra sveitarmanna (Landnámabók 1968,124 f.).

(Thorolf [...] Mostrarskegg [...] war ein großer Opferer und glaubte an Thor [...] warf er seine Hochsitzsäulen über Bord; darin war Thors Bild geschnitten. Dazu sprach er den Wunsch aus, Thor solle dort an Land kommen, wo er wolle, daß sich Thorolf ansiedeln solle, [...] sie hieß jetzt Thorsnes [...] Dort auf dem Vorgebirge [...] fällte Thorolf alle Urteile, und es wurde dort ein Bezirksthing mit Zustimmung aller Männer der Nachbarschaft errichtet).

Bei diesem Thing ist es später zu blutigen Auseinandersetzungen gekommen, und der Thingplatz wurde durch Blut des Hasses entweiht. Für den Thing wurde dann ein neuer Ort gefunden, und so wird die neue Thingstätte beschrieben:

[...] Var par pá helgistaðr mikill, ok par stendr enn Pórssteinn, er beir brutu pá menn um, er beir blótudu, ok par hjá er sá dómhringr, er menn skyldu til blóts daema (Landnámabók 1968, 126).

(Dort war damals eine große Friedensstätte, und es steht dort noch der Thorsstein, auf dem sie den Menschen, die sie opferten, das Rückgrat brachen; und dabei ist der Gerichtsring, in dem die Menschen zum Opfertode verurteilt wurden).

Diese Beschreibung im Landnámabuch ist einfach und unparteiisch. Thorolf Mosterbart wird als mächtiger Häuptling beschrieben und sein Stamm durch Generationen bis zu den Zeitgenossen der Landnámaschreiber geführt. Die Schreiber des Land náma machen keine Bemerkungen zu dem Opfer an der Thingstätte und die Menschenopferung wird als selbstverständlich beschrieben (Landnámabók 1968, 126).

Aus den Erzählungen des Landnáma über Thorolf Mosterbart wird deutlich, welch enge Beziehung zwischen dem Opfer und den Aufgaben des Häuptlings im Thing bestand (Aðalsteinsson 1985, 33). Aus den Erzählungen des Landnáma wird ganz klar, daß das Thing und die 
Opferstätte gleich heilig waren, und daß Opfer genauso im Thing wie im Tempel veranstaltet wurden. Und als das Thing mit dem Blut des Hasses entweilht worden war, gab es keine andere Möglichkeit, als das Thing auf einen anderen, reinen Ort zu verlegen.

An einigen Stellen in dem Landnahmebuch wird erwähnt, daß man auch Gegenständen, Bäumen, Steinen oder Wasserfällen Opfer gebracht habe. So steht z. B. über Thorir:

pórir [...] bjó at Lundi; hann blótaði lundinn (Landnámabók 1968, 270 f.). (Thorir [...] wohnte in Lund (d.h. Hain); er brachte dem ITain dort Opfer dar).

über Eyvind:

Eyvindr [...] nam Flateyjardal upp til Gunnsteina ok blótaði pá (Landnámabók 1968, 273).

(Eyvind nahm Flateyjardal zu den Gunnsteinen und brachte den Steinen dort Opfer dar).

über Thorstein Rotnase:

Porsteinn rauðnefr var blótmaðr mikill; hann blótaði forsinn ok skyldi bera leifar allar á forsinn (Landnámabók 1968, 358).

(Thorstein Rotnase war ein großer Opferer. Er opferte einem Wasserfall, in den er alle Speisereste trug).

Früher waren die Forscher der Meinung, daß die oben erwähnten Aufzeichnungen den Abgang des germanischen Glaubens bezeugten. In der letzten Periode des germanischen Glaubens hätten die Menschen nicht mehr nur noch die Götter, sondern auch Gegenstände und übernatürliche Phänomene angebetet, denen auch Opfer gebracht worden seien (Helgason 1925, 377; Ólsen 1900, 8). Die Erklärung zu dieser Annahme kann man zum Teil in den christlichen Gesetzessammlungen aus den ersten Jahrhunderten nach der Christianisierung suchen, in denen ganz besonders verboten wird, verschiedenen "heidnischen Schutzgeistern", wie sie dort genannt werden, Opfer zu bringen. In den Gesetzen werden Opfer an diese heidnischen Schutzgeister dem Aberglauben und unerlaubten Zauberkünsten gleichgestellt.

Jüngere Forscher haben die Aufzeichnungen über Thorir, Eyvind und Thorstein Rotnase nicht so wortwörtlich genommen, wie das früher der Fall war. Diese jüngeren Forscher hielten für wahrscheinlicher, daß es hier um verblaßte Überlieferungen geht. Diese Notizen enthielten dann nichts weiter, als daß die erwähnten Individuen ihr Opfer an den genannten Stätten veranstaltet hätten. Thorir habe seinem Gott im 
Hain Opfer gebracht, Eyvind an den Gunnsteinen, und als Thorstein Rotnase Reste in den Wasserfall getragen hatte, dann sei das nur eine der vielfältigen Gottesanbetungen eines großen Opferers gewesen, ein Teil von seiner Gesamtanschauung, wo das Natürliche und das Übernatürliche ein Ganzes gebildet hätten (Aðalsteinsson 1978, 29 f.).

In einigen Opferberichten des Landnáma steht, daß Opfer manchmal mit einem bestimmten $Z$ weck veranstaltet worden seien. So steht dort z. B. über Hallstein:

Hallsteinn son Pórólfrs Mostrarskeggs [...] bjó á Hallsteinsnesi; hann blótað̋ par til pess, að $\mathbf{P}$ orr sendi honom öndvegissúlur ok gaf par til son sinn. Eptir pat kom tré á land hans, pat var sextigi ok priggja álna ok tveggja faðma digrt; pat var haft til öndvegissúlna, ok eru par af görvar öndvegissúlur nær á hverjum bø um pverfjörðuna. Dar heitir nú Grenitrésnes, er tréit rak á land (Land námabók 1968, 163 f.).

(Hallstein, ein Sohn des Thorolf Mostrarskegg, [...] wohnte auf Hallsteinsnes. Er opferte Thor seinen eigenen Sohn, daß er ihm Hochsitzsäulen sende. Darauf trieb ein Baumstamm ans Land, der war dreiundsechzig Ellen lang und zwei Faden dick. Der wurde zu Hochsitzsäulen verwendet, und es sind daraus die Hochsitzsäulen fast auf allen Gehöften in den Querfjorden gemacht. Die Stelle, wo der Baumstamm an Land trieb, heißt jetzt Grenitresnes (Fichtenbaumkap)).

Der Text hier oben wurde dem Hauksbuch entnommen. Im Sturlubuch befindet sich diese Notiz zum größten Teil übereinstimmend, nur und das spielt schon eine Rolle - fehlen dort die Worte "opferte seinen eigenen Sohn", die aller Wahrscheinlichkeit nach in dem Styrmisbuch vorhanden waren. Es ist nicht völlig klar, was diese Worte bedeuten, aber hier sind sie so verstanden worden, daß Hallstein seinen eigenen Sohn geopfert habe. Andererseits gibt es die Erklärung, daß Hallstein seinen Sohn dem Thor ganz besonders gewidmet habe. (Aðalsteinsson 1971, 33 und Zitate). Aller Wahrscheinlichkeit nach hat Sturla diese Worte aus seinem Buch weggelassen weil sie ihm irgendwie anstößig erschienen.

Es gibt eine andere Opfernotiz, die weder im Sturlubuch noch im Hauksbuch verzeichnet ist, und es wird demnach angenommen, daß es sie auch im Styrmisbuch nicht gegeben hat. In den MelabuchÜberbleibseln (Melabókarslitrin) heißt es nämlich über Thorolf Höllenhaut:

Pórólfr heljarskinn nam Forsceludal [...] hann blótaði mönnum (Landnámabók 1921, 94; Landnámabók 1958, 94; Landnámabók 1925, 98). 
(Thorolf Höllenhaut nahm Forsæludal (Schattentale) [...] er opferte Männer).

Der Schreiber des Landnáma macht keine Bemerkung zu dieser Notiz, aber wir können annehmen, daß sie aus den späteren Fassungen verchwunden ist, weil sie deren Schreibern anstößig vorgekommen war.

In der Erzählung des Landnáma über Hrolleif und Ljót, seine Mutter, wird ein Opfer erwähnt, und es wurde angenommen, daß dieses Opfer mit besonderem Zweck veranstaltet wurde. Hrolleif hat den alten Siedler Ingimund umgebracht. Thorstein, Ingimunds Sohn, und seine Brüder überfielen Ljót und Hrolleif. Sie hatten einen Kundschafter zum Gehöft geschickt, der soll angeklopft und dann zwölf Strophen vorgesagt haben dort, bis die Tür geöffnet wurde. Dann heißt es:

[...] ok sá fatahrúgu á bröndum, ok kom undan rautt kląði. Porsteinn kvað bar verit hafa Hrolleif, - "ok mun Ljót hafa blótat til langlifis honum." (Landnámabók 1968, 221 f.).

[...] und sah einen Kleiderhaufen neben dem Herd und ein rotes Gewand darunter hervorkommen. Thorstein meinte, da sei Hrolleif gewesen, "und Ljot werde für sein langes Leben geopfert haben.").

Thorstein und seine Brüder gingen nun zum Gehöft und töteten Hrolleif. Und es wird fortgesetzt:

\á var Ljót út komin ok gekk öfug; hon hafðð höfuðit millum fóta sér, en klaðin á baki sér. Jökull hjó höfuð af Hrolleifi ok rak i andlit Ljótu. Pá kvazk hon of sein orðit hafa, - "nú mundi um snúask jörðin fyrir sjónum. mínum, en pér munduð allir arzk hafa" (Landnámabók 1968, 222).

(Inzwischen war Ljot herausgekommen; sie schritt verkehrt einher, den Kopf zwischen den Beinen und die Kleider auf dem Rücken. Jökul hieb Hrolleif den Kopf ab und warf ihn Ljot ins Gesicht. Da rief sie, sie sei zu langsam gewesen: "Sonst würde sich jetzt der Erdboden umgedreht haben bei meinem Anblick, und ihr wärt alle toll geworden.").

In dieser Erzählung wird zu verstehen gegeben, daß die Opferzeremonie der Ljót viel eher Zauber als eine Glaubenszeremonie gewesen sei. Es ist bemerkenswert daß es Ljót ist, die Mutter von Hrolleif, die das Opfer veranstaltet, Die Sympathie des Landnámaschreibers gehört aber ganz Thorstein Ingimundarson und seinen Brüdern.

Zauber und Magie werden wir aber auch in anderen Opfernotizen des Landnáma gewahr. Es wird von Vebjörn erzählt, der bei seiner Landung in Island ein Opfer veranstaltete. Landnáma berichtet davon folgendermaßen: 
Pá fekk Vébjörn at blóti miklu ok kvad Hákon jarl blóta pann dag peim til ópurflar. En er hann var at blótinu, eggjuðu bræðr hans hann til brottfarar, ok gádu peir eigi blótsins, ok létu peir út. Deir brutu hinn sama dag skip sitt undir hömrum miklum í illvidri (Landnámabók 1968, 189).

(Da veranstaltete Vebjörn ein großes Opfer; er meinte, Jarl Hakon opfere an diesem Tage zu ihrem Verderben. Aber als er beim Opfer war, trieben ihn seine Brüder zur Weiterfahrt an, und er ließ das Opfer im Stich, und sie gingen in See. Denselben Tag scheiterte ihr Schiff bei schwerem Sturm an großen Klippen).

Die Aufzeichnung über Vebjörns Opfer ist nicht deshalb bewahrt worden, weil es so bedeutend sein sollte, daß er dieses Opfer veranstaltete, sondern das, was dem Opfer folgte, war so interessant, daß es in Erinnerung behalten wurde. Und da diese Ereignisse in direkter Beziehung zu der Opferung stehen, ist nur selbstverständlich, daß auch das Opfer mit in die Erzählung aufgenommen wurde. Der Schiffbruch und die Lebensgefahr, in die Vebjörn und seine Leute geraten waren, ist zweifellos als direkte Folge dessen, ausgelegt worden, daß er seine Opferung nicht zu Ende geführt habe, er Ließ das Opfer im Stich, wie es dort heißt. Hätte Vebjörn sein Opfer nicht im Stich gelassen, hätte erwartet werden können, daß der Gott ihn in seiner Antwort auf das Opfer vor der Gefahr gewarnt hätte, die ihn an der Küste erwartete.

In dem Bericht von Vebjörns Opfer gibt es noch etwas Interessantes, und zwar die Behauptung von Vebjörn, daß Jarl Hakon in Norwegen an demselben Tag zu ihrem Verderben opfere. Diese Bemerkung erscheint sowohl im Hauksbuch als auch im Sturlubuch. Aber in dem dritten Belegmaterial, in dem Geirmundarthattur das Vebjörns Opfer und Seenot auch beschreibt (Sturlunga saga 1906-11, 1, 5), kommt diese Bemerkung nicht vor. Es ist nachgewiesen worden, daß Geirmundarthattur das älteste der Belegmaterialien ist, das von Vebjörn erzählt (Aðalsteinsson 1986, 35). Die Notiz über das Opfer ist also in den jüngeren Belegmaterialien gewissermaßen zu einer Erzählung von Zauberkünsten geworden, am wahrscheinlichsten im dreizehnten Jahrhundert. Aller Wahrscheinlichkeit nach erschien es zu der Zeit notwendig, zu erklären, warum die Siedler Opfer veranstaltet hatten, als sie ans Land gekommen waren. Soviel wir wissen, war ein solches Opfer nach den ältesten Schriften selbstverständlich. 
Ich wende mich jetzt den Opfernotizen in den Isländersagas zu. Zuerst untersuche ich einige Erzählungen über Personen und Ereignisse, die wir in den Erzählungen des Landnáma kennengelernt haben.

In der Eyrbyggjasaga wird von Thorolf Mosterbart erzählt und von seinen geistlichen und weltlichen Beshäftigungen. Thorolf wird in der Eyrbyggjasaga im großen und ganzen sehr ähnlich beschrieben wie in Landnáma, und die Einstellung zur nordgermanischen Religion ist fast die gleiche in beiden Schriften. In der Eyrbyggjasaga steht:

Pórólfr Mostrarskegg fekk at blóti miklu ok gekk till fréttar við pór [...] en fréttin vísadi Pórólfi til Íslands [...] \$ar sem Đórr hafð̉ á land komit, á tanganum nessins, lét hann hafa dóma alla ok setti par heraðsping; par var svá mikill helgistaðr, at hann vildi með engu móti láta saurga vollinn [...] \$órólfr gerðisk rausnarmaðr [...] $\mathbf{p}$ ar sér en dómhring pann, er menn váru da mdir í til blóts; í peim hring stendr pórs steinn, er peir menn váru brotnir um, er til blóta váru hafðir, ok sér enn blódslitinn á steininum. Var á pví pingi inn mesti helgistaðr [...] (Eyrbyggja saga 1935, 7, 10, 18).

(Thorolf Mosterbart veranstaltete ein großes Opferfest und fragte Thor [...] des Gottes Bescheid aber wies Thorolf nach Island [...] Dort aber, wo das Thorsbildnis ans Land gekommen war, auf dem schmalsten Ausläufer der Landspitze, ließ er alle Gerichtsversammlungen abhalten und legte dorthin ein Bezirksthing. So heilig aber war ihm die ganze Stätte, daß er das Feld daselbst auf keine Weise besudeln lassen wollte [...] Thorolf hielt ein prächtiges Haus [...] Dort ist noch der Gerichtskreis zu sehen, in dem die Männer zur Opferung verurteilt wurden. In diesem Kreis steht der Thorsstein, an dem den zum Opfer bestimmten Männern das Rückgrat gebrochen wurde, und noch ist die Blutfarbe an dem Stein zu sehen. Dieser Thingplatz war eine sehr heilige Stätte $[\ldots])$.

Forscher waren sich schon lange im klaren darüber daß zwischen den Erzählungen über Thorolf Mosterbart in dem Landnáma und in der Eyrbyggja eine enge Beziehung bestand. Sie waren sich nur nicht einig darüber, welche von den beiden Schriften Material aus der anderen übernommen hatte (Jóhannesson 1941, 93 f.; Landnámabók 1968, 124 und Zitate; Aðalsteinsson 1985, 24 ff.). Es wird allgemein angenommen, daßs die Eyrbyggjasaga Mitte des dreizehnten Jahrhunderts geschrieben wurde, und es ist nachgewiesen worden, daß sie vieles aus anderen Schriften übernahm, z. B. aus der Heimskringla (Aðalsteinsson 1985, 24 ff. und Zitate). Wenn man die Einstellung zu Opfer und zu nordgermanischer Religion untersucht, ergibt sich die logische Schlußfolgerung, daß das Material über Thorolf Mosterbart 
aus dem Landnáma in die Eyrbyggjasaga übernommen wurde. Was diese Einstellung betrifft, unterscheidet sich die Eyrbyggjasaga von anderen aus dem dreizehnten Jahrhundert stammenden Isländersagas, was später noch näher erläutert werden wird. Die einfachste Erklärung dafür wäre, daß die aus dem Landnáma übernommenen Erzählungen aus dessen ältesten Fassungen stammen, und daß die Eyrbyggjasaga in ihren Erzählungen dem Landnahmebuch näher kommt als andere Isländersagas.

In der Vatnsdælasaga, wahrscheinlich um 1279 geschrieben, gibt es eine Aufzeichnung über Hrolleif und seine Mutter. Dort steht folgen des:

Hann kvazk sét hafa hrúgu eina mikla ok koma undan fram rautt klæði. Dórsteinn mælti: "\$ar muntu sét hafa Hrolleif ok blótklæđi hans [...] Peir sá hús standa litit fyrir dyrum ok hlid i milli ok heimaduranna. Pórsteinn mœlti: "Petta mun vera blóthús, ok mun Hrolleifi hingat cetlat, pá er hon hefir fullgört sitt efni ok allan sinn fjändskap [...]" [...] mælti Högni: "Hvat fjánda fer hér at oss, er ek veit eigi hvat er?" Pórsteinn svarar: "Par ferr Ljót kerling ok hefir breytiliga um búizk;" - hon haföi rekit fötin fram yfir höfud sér ok fór öfug ok rétti höfudit aptr milli fótanna; ófagrligt var hennar augnabragd, hversu hon gat peim trollsliga skotit [...] Hon kvazk hafa atlat at snúa par um landslagi öllu, - "en pér æerdizk allir ok yrdid að gjalti eptir á vegum úti med villidýrum (Vatnsdæla saga 1939, 68 ff.).

(Er sagte, er habe einen großen Packen gesehen und unten ein rotes Kleid herauskommen. Thorstein sprach: "Da wirst du Hrolleif und sein Opfergewand gesehen haben [...]" [...] sie sahen ein Häuschen vor der Tür stehen und einen freien Raum zwischen ihm und der Haustür. Thorstein sprach: "Das wird das Opferhaus sein, und Hrolleif wird hier hineingehen sollen, wenn die Alte ihre Sachen und ihr Teufelswerk erledigt hat [...] sprach Högni: "Was für ein Teufel kommt dort auf uns zu? Ich weiß nicht, was es ist." Thorstein erwiderte: "Da kommt Ljót, das alte Weib, und hat sich sonderbar geputzt." Sie hatte sich die Kleider vorn über den Kopf zwischen den Beinen nach hinten. Greulich war der Blick ihrer Augen, wie sie ilnn wie die Trolle zu schießen wußte. [...] Sie sagte, sie habe das ganze Land umstürzen wollen: - "und ihr wäret alle toll geworden und verrückt draußen bei den wilden Tieren geblieben [...]").

Vatnsdælasaga erzählt außerdem von Thorolf Höllenhaut, der laut Melabuch im Schattental gewohnt und Menschen geopfert haben soll. In der Vatnsdælasaga steht, daß Thorolf zuerst im Schattental gewohnt habe, aber später zum Friðmundarfluß umgezogen sei, und sich dort eine Burg gebaut habe. Dann heißt es: 
Pórólfr (heljarskinn) lagðisk á fé manna ok gerððisk hinn mesti pjófr; hann átti blótgrafar, pví at menn hugðu at hann blótaði bað̇ mönnum ok fé (Vatnsdæla saga 1939, 82).

(Thorolf (Höllenhaut) machte sich an das Vieh der Leute und wurde der schlimmste Dieb; er hatte auch Opfergruben, denn die Leute glaubten, daß er Menschen und Vieh opferte).

Thorstein Ingimundarsson hat mit seinen Brüdern Thorolf überfallen, und Jökull Ingimundarsson ist es gelungen, in die Burg zu gelangen. Und es wird weitererzählt:

Pórólfr kom upp ór blótgrof sinni ok hljóp ór virkinu, en Jökull eptir honum [...] En er Pórólf sá, at hann myndi eigi komask undan, bá settisk hann niðr i mýrinni ok grét [...] Jökull kom pá at honum ok kvað hann vera mikla mannfýlu ok illmenni, en pó engan próttinn í. Jökull hjó hann pá banahögg [...] Peir fóru heim braðr eptir petta ok höfðu unnit mikla heraðsbót i drápi Pórólfs heljarskinns (Vatnsdæla saga 1939, 83 f.) .

Thorolfr tauchte aus seiner Opfergrube auf und sprang aus der Burg, aber Jökul ihm nach [...] Aber als Thorolf sah daß er nicht entweichen konnte, da setzte er sich im Moore nieder und weinte [...] Jökul trat zu ihm und schalt ihn einen Schurken und Bösewicht und einen Kerl ohne Mut. Jökul versetzte ihm den Todeshieb. [...] Darauf zogen die Brüder heim und hatten dem Gau grosse Hilfe gebracht durch die Tötung Thorolfs Höllenhaut).

Es ist interessant, die Beschreibungen des Landnáma von Thorolf Mosterbart und von Thorolf Höllenhaut mit den Beschreibungen der Eyrbyggjasaga und Vatnsdælasaga von denselben Personen zu vergleichen. Laut Landnáma besteht kein großer Unterschied zwischen der Handlungsweise und den Taten dieser zwei Menschen. Beide waren Opferer und beide opferten Menschen gemäß Landnáma, weil wir doch annehmen müssen, daß Thorolf Mosterbart an den Opferungen teilgenommen hat auf dem Thing, das er in Thorsnes gegründet hatte.

Aus den Erzählungen verschiedener Isländersagas über dieselben Personen wird folgendes deutlich: in der Eyrbyggjasaga ist Thorolf Mosterbart derselbe große Opferer wie in Landnáma, aber die Saga sieht nichts Anstößiges an seinem Opfer. Er ist ein großer Häuptling und geachtet von seinen Zeitgenossen und Nachkommen trotz seiner Opfer, und der Autor der Eyrbyggjasaga macht keinen Versuch, die Opfer des Thorolf Mosterbart zu vertuschen. Aus den Erzählungen der Vatnsdælasaga über Thorolf Höllenhaut kann man etwas ganz anderes herauslesen. Dort wird Thorolf Höllenhaut als großer Dieb beschrieben, u.a. wegen seiner Opfer. Weiterhin wird er als Schurke 
und Bösewicht gestempelt, und zugleich als ein Kerl ohne Mut, mit dessen Tötung man dem Bezirk ein Gefallen tun würde.

Wie schon früher erwähnt, wurden Eyrbyggjasaga und Vatusdælasaga zu ähnlicher Zeit geschrieben, um 1250-1270. Es ist nicht sehr wahrscheinlich, daß in diesen 10 Jahren die Einstellung zu Opfer und Opferern sich grundlegend geändert hätte. Mir scheint deshalb alles darauf hinzuweisen, daß die Erzählungen der Eyrbyggjasaga über Thorolf Mosterbart aus einer alten Landnámafassung von der ersten Hälfte des 12. Jahrhunderts dorthin gelangt sind, wogegen die Erzählungen der Vatnsdælasaga über Thorolf Höllenhaut durch die Ideologie der kirchlichen Geschichtsschreibung des 12. und des 13. Jahrhunderts geprägt sind (Nordal 1973, 103-131; Lárusson 1967, 80 ff.).

Abschließend kommen hier Zitate aus zwei der jüngsten Isländersagas, aus der Njálssaga und aus der Hrafnkels Freysgodasaga; wahrscheinlich stammen beide aus den letzten Jahrzehnten des 13. Jahrhunderts. In der Njálssaga wird folgendermaßen davon berichtet wie Thangbrand der Missionar von den Ostfjorden zum Althing ging:

Maðr hét Galdra-Heðinn ok bjó í Kerlingardal. Par keyptu heiðnir menn at honom at hann skuldi deyða Dangbrand ok föruneyti hans, ok fór hann upp á Arnarstakksheiði ok elfdi blót mikit. $\mathbf{\mathrm { P } a}$ er $\mathbf{\mathbf { P }}$ angbrandr reið austan, pá brast sundr jordin undir hesti hans, en hann hljóp af hestinum ok komsk upp á bakkann, en jörðin svalg hestinn [...] (Brennu-Njáls saga 1954, 259). (Es war ein Mann namens Zauber-Hedin, der hatte seine Wirtschaft im Altweibertal: den bezahlten die Heiden dafür, daß er den Tod Thangbrands und seines Gefolges bewirken sollte. Er zog hinauf auf die Önnsrockheide sie von Osten beritt, da barst die Erde unter seinem Pferd, er aber sprang vom Pferde und gelangte auf den Klufstrand hinauf, aber die Erde verschlang das Pferd [...]).

Zauber-Hedin trägt seinen Namen offenbar mit Recht, und das große Opfer, von dem erzählt wird, ist eindeutig und vor allem eine Zauberzeremonie. Es ist in diesem Zusammenhang noch interessant zu bedenken, daß diese Erzählung möglicherweise eine Erklärung einer alten Geschicte ist, die tatsächlich stattgefunden hat (Torarinsson 1968, 21; Nordal 1928, 113). Der Ursprung der Geschichte ändert aber nichts an der Einstellung zu Opferungen, was ja in der Untersuchung, die hier durchgeführt wird, am wichtigsten ist. Die Glaubenskultur des 13. Jahrhunderts hat die Opferung, von der in der Njálssaga erzählt wird, in Zauber umgeändert.

In dem zweiten Teil der Hrafnkels Freygodasaga wird die Einstellung der Hauptperson zum Opfer folgendermaßen geschildert: 
Hrafnkell spurði austr i Fljótsdal, at bjóstarssynir höfðu týnt Freyfaxa ok brennt hofit. Dá svarar Hrafnkell; "Ek hygg pat hégóma at trúa á goð," ok sagðisk hann paðan af aldri skyldu á goð trúa, ok pat efndi hann siðan at hann blótaði aldri (Hrafnkels saga 1950, 124).

(Drüben im Fließtal hörte Hrafnkel, daß die Thjostarsöhne Freyfaxi ertränkt und den Tempel verbrannt hatten. Da sagt er: "Dummes Zeug der Glaube an die Götter," und erklärte, von jetzt an nicht mehr auf Götter zu vertrauen. Er handelte auch danach, opferte niemals mehr).

Es ist eindeutig, daß der Autor der Hrafnkelssaga Hrafnkels Entscheidung, mit den Opferungen aufzuhören, sehr positiv bewertet. Laut der Erzählung gelingt ihm auch alles von da an. Hier ist die christliche Einstellung zum Opfer ganz eindeutig, es ist dieselbe Einstellung, die in den Sagaschriften vom 12. und 13. Jahrhundert überall zum Ausdruck kommt. Diese Einstellung ist besonders auffallend in den Schriften, die unter der Aufsicht der Kirche zusammengestellt wurden.

\section{III}

Bis jetzt habe ich mich mit Opfernotizen im Landnáma und einigen Isländersagas befaßt. Im Landnáma habe ich die meisten Stellen untersucht, wo ein Opfer erwähnt wird, aber aus den Isländersagas habe ich nur einige Geschichten zum Vergleich ausgewählt. Ich habe versucht, die Erzählungen nach geschätztem Alter zu orden, und setzte dabei ganz nach vorn die Erzählungen, die aller Wahrscheinlichkeit nach am ältesten sind. Hier muß man aber selbstverständlich mit Vorbehalt vorgehen, da es schwierig sein kann, das alter einzelner Erzählungen zu schätzen. Bei der Altersbestimmung einzelner Glaubensgeschichten kann man sich am ehesten danach richten, ob bestimmte Religionen sie offensichtlich rechtfertigen oder verurteilen. Mir scheint eindeutig, daß die Erzählungen, in denen die Bedeutung des Opfers besonders betont wird, im zehnten Jahrhundert entstanden sein müssen, genau wie die Erzählungen, die das Opfer verurteilen, zur Zeit des Christentums entstanden. Auf Grund dieser Hauptregel habe ich anderswo Beweise dafür erbracht, daß die Geschichten über Flóki, Ingólf und Vebjörn alle im zehnten Jahrhundert entstanden sind (Aðalsteinsson 1989). Einige der Erzählungen im Landnáma sind, was Religionen betrifft, vollkommen neutral und erzählen von Opferungen wie von selbstverständlichen Vorgängen. Diese Erzählungen scheinen geschichtlich Wissenswertes zu beinhalten, und daher kann man eigentlich die Schlußfolgerung ziehen, daß sie sehr früh in der Sagazeit 
geschrieben worden sind oder noch bevor die Kirche angefangen hat $\mathrm{zu}$ veranlassen, daß die Opferungen als solche, und ganz besonders die Opferer, verurteilt werden sollten. Zu dieser Gruppe gehören die Erzählungen des Landnáma über Thorolf Mosterbart, Thorir, Eyvind, Thorstein Rotnase, Hallstein Thorolfsson und Thorolfr Höllenhaut. In die dritte Gruppe kämen dann die Opfernotizen, in denen die Opferungen als negativ, und diejenigen, die sie veranstalten, als tadelnswert angesehen werden. Von den Erzählungen des Landnáma kann man die Aufzeichnung über Ljót und Hrolleif, ihren Sohn, zu dieser Gruppe zählen, und das gleiche gilt für die Stellen, wo die Schreiber des Landnáma Sätze oder Satzteile, in denen Opfer erwähnt wurde, weggelassen haben. Diese Eigenart kommt aber in den Isländersagas viel deutlicher zum Vorschein, ausgenommen in der Eyrbyggjasaga. Aus anderens Isländersagas sind Beispiele für die sehr negative Einstellung Opferungen und Opferern gegenüber, und zugleich Beispiele dafür, wie positiv die Aufgabe der Opferungen bewertet wurde, geliefert worden. Diese Beispiele zeigen alle eine natürliche religionsgeschichtliche Entwicklung, können aber gleichzeitig als Vergleich verwendet werden, wenn es darum geht, das Alter einzelner Erzählungen in den Schriften zu bestimmen.

In Betracht dessen, was hier vorgetragen wurde, möchte ich zum Schluß klarmachen, daß eine grundsätzliche Revision der Landnámauntersuchungen meiner Meinung nach äußerst dringend ist. Ich denke hier vor allem daran, daß bei den Untersuchungen neue Methoden angewendet werden sollten. Landnámaspezialisten haben bis jetzt vor allem mit philologischen Untersuchungsmethoden gearbeitet, und auf solcher Grundlage ruhen die Resultate, die über den inneren Zusammenhang einzelner Landnámafassungen und über den Quellenwert einzelner Schriften vorgelegt wurden. Bei den Landnámauntersuchungen wurden bis jetzt keine folkloristischen und religionsgeschichtlichen Untersuchungsmethoden verwendet, die, meiner Meinung nach, viel wahrscheinlicher zu brauchbaren Resultaten führen würden, als die Philologie, wenn es um ein Werk wie Landnáma geht.

Es gibt sichere Belegmaterialien dafür, daß um 1100 in Island allgemeine Wißbegierde geherrscht hat und vor allem Interesse an Menschen und Familien. Ari der Gelehrte erzählt, als er von der Materialsammlung für das Isländerbuch berichtet, $\mathrm{d} a ß$ er seine $\mathrm{N}$ achrichtenquellen aufgesucht und aus ihren Reihen diejenigen ausgewählt habe, die "kundig aber nicht lügnerisch und äußerst weise" gewesen seien. Aris des Gelehrten Einschätzung der Bezugsquellen zeigt uns, daß die mündliche Überlieferung seiner Tage gleichzeitig sicher und unsicher 
war, und daß man dort mit größter kritischer Vorsicht auswählen mußte. Das aber, daß Ari selber so anspruchsvoll sein konnte, weist auch darauf hin, daß die mündliche Überlieferung $z u$ der Zeit in Island äußerst lebendig war.

Es ist äußerst dringend, diese lebendige mündliche Überlieferung von ungefähr $1100 \mathrm{zu}$ untersuchen und so verschiedenen Problemen auf den Grund zu gehen, die mit der Entstehung des Landnáma in Zusammenhang stehen sowie mit der Bewahrung verschiedener früher Erinnerungen, die das Landnámabuch enthält. Wahrscheinlich würde gerade eine solche untersuchung neues und besseres Licht auf die Opfernotizen werfen, und dadurch würden wir ihre Bedeutung noch besser als früher schätzen lernen, sie zum Verständnis der Beziehungen zwischen der nordgermanischen Religion und des Christentums verwerten können.

\section{Literat urverzeichnis}

Aðalsteinsson, J. H. 1971. Kristnitakan á Íslandi. Reykjavík.

- 1978. Under the cloak. Uppsala.

- 1985. Blót and Ping. Temenos 21. Turku.

- 1986. The position of freed slaves in Medieval Iceland. (Saga-Book 22.) London.

- 1989. 900-talssägner i Landnámabok. Folklore \& Folkkultur. Reykjavík.

Brennu-Njáls saga. 1954. [Hrsg. von] E. Ól. Sveinsson. (Íslenzk fornrit 12.) Reykjavík.

Eyrbyggja saga. 1935. [Hrsg. von] E. Ól. Sveinsson. (Íslenzk fornrit 4.) Reykjavík.

Helgason, J. 1925. Kristnisaga Íslands frá öndverðu til vorra tíma 1 . Reykjavík.

Hrafnkels saga Freysgoða. 1950. [Hrsg. von] J. Jóhannesson. (Íslenzk fornrit 11.) Reykjavík.

Jóhannesson, J. 1941. Gerðir Landnámabókar. Reykjavík.

Landnámabók. Íslendingabók. Landnámabók. 1968. [Hrsg. von] J. Benediktsson (Íslenzk fornrit 1.) Reykjavík.

Landnámabók Íslands. 1925. [Hrsg. von] F. Jónsson. København.

Landnámabók Melabók AM 106.1921. 112 Fol. [Hrsg. von] F. Jónsson. København.

Landnámabók Skarðsárbók. 1958. [Hrsg. von] J. Benediktsson. Reykjavík.

Lange, W. 1968. Flókis Raben. (Studien zur europäischen Vor- und Frühgeschichte.) Neumünster.

Lárusson, M. M. 1967. Fródleiksp๕ettir og sögubrot. Hafnarfirði. 
Nordal, S. 1928. Pangbrandur á Mýrdalssandi. Festskrift til Finnur Jónsson 29. maj 1928. København.

- 1973. Snorri Sturluson. Reykjavik.

Ólsen, B. M. 1900. Um kristnitökuna á Íslandi árið 1000 og tildrög hennar. Reykjavík.

Pétursson, E. G. 1986. Efling kirkjuvaldsins og ritun Landnámu. Skírnir. Reykjavík.

Rafnsson, S. 1974. Studier i Landnámabok. (Bibliotheca Historica Lundensis 31.) Lund.

Sturlunga saga 1-2. 1906-11. [Hrsg. von] Kr. Kålund. København.

Pórarinsson, S. 1968. Heklueldar. Reykjavík.

Vatnsdala saga. 1939. [Hrsg. von] E. Ól. Sveinsson. (Íslenzk fornrit 8.) Reykjavík. 